\title{
One year monitoring of volatile organic compounds (VOCs) from an oil-gas station in northwest China
}

Huang Zheng ${ }^{1,2}$, Shaofei Kong ${ }^{2}$, Xinli Xing ${ }^{1,3}$, Yao Mao ${ }^{3}$, Tianpeng Hu ${ }^{1}$, Yang Ding ${ }^{1}$, Gang $\mathrm{Li}^{4}$, Dantong Liu ${ }^{5}$,

Shuanglin $\mathrm{Li}^{2}$, and Shihua Qi ${ }^{1,3}$

${ }^{1}$ Department of Environmental Science and Technology, School of Environmental Studies, China University of Geosciences, Wuhan, 430074, China

${ }^{2}$ Department of Atmospheric Sciences, School of Environmental Studies, China University of Geosciences, Wuhan, 430074, China

${ }^{3}$ State Key Laboratory of Biogeology and Environmental Geology, China University of Geosciences, Wuhan, 430074, China

${ }^{4}$ Karamay Environmental Monitoring Center Station, Karamay, 834000, China

${ }^{5}$ School of Earth and Environmental Sciences, the University of Manchester, UK, M13 9PL 
Table S1. Contributions of top ten species to ozone formation potential based on the Propy-Equiv and MIR scales.

\begin{tabular}{|c|c|c|c|c|c|}
\hline \multicolumn{3}{|c|}{ Propy-Equiv (ppbC) } & \multicolumn{3}{|l|}{ MIR (ppbv) } \\
\hline Compounds & Mean & SD & Compounds & Mean & SD \\
\hline 1-Pentene & 16.7 & 25.1 & $o$-Xylene & 40.4 & 60.7 \\
\hline 1-Hexene & 7.16 & 14.5 & $n$-Heptane & 30.2 & 56.1 \\
\hline Cyclopentane & 5.10 & 9.47 & Cyclopentane & 19.4 & 26.4 \\
\hline$n$-Heptane & 4.67 & 35.0 & $n$-Pentane & 18.5 & 27.5 \\
\hline$n$-Pentane & 4.24 & 5.96 & 1-Hexene & 18.2 & 25.5 \\
\hline Styrene & 4.12 & 26.7 & $n$-Nonane & 15.5 & 83.8 \\
\hline$i$-Pentane & 3.94 & 5.85 & Styrene & 13.7 & 19.3 \\
\hline cis-2-butene & 3.76 & 11.0 & 2,2-Dimethylbutane & 11.8 & 31.7 \\
\hline$n$-Butane & 3.66 & 4.98 & Benzene & 10.4 & 21.1 \\
\hline trans-2-butene & 3.66 & 8.13 & 1-Pentene & 10.0 & 14.7 \\
\hline
\end{tabular}


Table S2. Pearson coefficients between VOCs, source contributions, and meteorological parameters.

\begin{tabular}{|c|c|c|c|c|c|c|c|c|c|c|c|c|c|c|c|c|c|}
\hline & $\mathrm{F} 1$ & $\mathrm{~F} 2$ & $\mathrm{~F} 3$ & $\mathrm{~F} 4$ & F5 & $\mathrm{T}$ & $\mathrm{Re}$ & $\mathrm{P}$ & WS & BLH & VOCs & $\mathrm{SO}_{2}$ & $\mathrm{NO}_{2}$ & $\mathrm{CO}$ & $\mathrm{O}_{3}$ & $\mathrm{PM}_{2.5}$ & $\mathrm{PM}_{10}$ \\
\hline $\mathrm{F} 1$ & 1 & & & & & & & & & & & & & & & & \\
\hline $\mathrm{F} 2$ & $0.49 * *$ & 1 & & & & & & & & & & & & & & & \\
\hline F3 & $0.29 * *$ & $0.67 * *$ & 1 & & & & & & & & & & & & & & \\
\hline $\mathrm{F} 4$ & $0.47 * *$ & $0.15^{* *}$ & 0.04 & 1 & & & & & & & & & & & & & \\
\hline F5 & $0.50 * *$ & $0.80 * *$ & $0.65^{* *}$ & $0.14^{*}$ & 1 & & & & & & & & & & & & \\
\hline $\mathrm{T}$ & 0.05 & $-0.31 * *$ & $-0.57 * *$ & $0.11 * *$ & $-0.38 * *$ & 1 & & & & & & & & & & & \\
\hline $\operatorname{Re}$ & -0.01 & $0.30 * *$ & $0.53 * *$ & $-0.17 * *$ & $0.37 * *$ & $-0.86 * *$ & 1 & & & & & & & & & & \\
\hline $\mathrm{P}$ & -0.05 & $0.25 * *$ & $0.46^{* *}$ & $0.18 * *$ & $0.32 * *$ & $-0.92 * *$ & $0.76^{* *}$ & 1 & & & & & & & & & \\
\hline WS & $-0.12 *$ & $-0.39 * *$ & $-0.44 * *$ & 0.03 & $-0.37 * *$ & $0.51 * *$ & $-0.51 * *$ & $-0.48 * *$ & 1 & & & & & & & & \\
\hline BLH & -0.08 & $-0.42 * *$ & $-0.55^{* *}$ & 0.04 & $-0.40 * *$ & $0.81 * *$ & $-0.68 * *$ & $-0.76^{* *}$ & $0.64 * *$ & 1 & & & & & & & \\
\hline VOCs & $0.48 * *$ & $0.74 * *$ & $0.58 * *$ & 0.07 & $0.72 * *$ & $-0.26 * *$ & $0.20 * *$ & $0.17 * *$ & $-0.39 * *$ & $-0.45^{* *}$ & 1 & & & & & & \\
\hline $\mathrm{SO}_{2}$ & $0.15^{* *}$ & $0.15 * *$ & $0.12 *$ & -0.04 & $0.15^{* *}$ & 0.09 & $-0.16^{* *}$ & $-0.14 * *$ & -0.06 & -0.003 & $0.15^{*}$ & 1 & & & & & \\
\hline $\mathrm{NO}_{2}$ & $0.33 * *$ & $0.45 * *$ & $0.49 * *$ & $0.12 *$ & $0.37 * *$ & $-0.36 * *$ & $0.34 * *$ & $0.39 * *$ & $-0.45 * *$ & $-0.54 * *$ & $0.46 * *$ & 0.10 & 1 & & & & \\
\hline $\mathrm{CO}$ & $0.21 * *$ & $0.44 * *$ & $0.59 * *$ & 0.041 & $0.35^{* *}$ & $-0.48 * *$ & $0.48 * *$ & $0.44 * *$ & $-0.44 * *$ & $-0.50 * *$ & $0.34 * *$ & $0.11 *$ & $0.61 * *$ & 1 & & & \\
\hline $\mathrm{O}_{3}$ & $-0.17 * *$ & $-0.27 * *$ & $-0.33 * *$ & -0.02 & $-0.28 * *$ & $0.63 * *$ & $-0.58 * *$ & $-0.66 * *$ & $0.29 * *$ & $0.55 * *$ & $-0.18 * *$ & $0.24 * *$ & $-0.60 * *$ & $-0.48 * *$ & 1 & & \\
\hline $\mathrm{PM}_{2.5}$ & $0.13^{*}$ & $0.43 * *$ & $0.77 * *$ & 0.04 & $0.44 * *$ & $-0.59 * *$ & $0.54 * *$ & $0.47 * *$ & $-0.48 * *$ & $-0.54 * *$ & $0.39 * *$ & $0.22 * *$ & $0.50 * *$ & $0.60 * *$ & $-0.28 * *$ & 1 & \\
\hline $\mathrm{PM}_{10}$ & $0.23 * *$ & $0.43 * *$ & $0.71 * *$ & 0.09 & $0.42 * *$ & $-0.36 * *$ & $0.30 * *$ & $0.24 * *$ & $-0.36 * *$ & $-0.43 * *$ & $0.49 * *$ & $0.28 * *$ & $0.48 * *$ & $0.53 * *$ & $-0.19 * *$ & $0.86^{* *}$ & 1 \\
\hline
\end{tabular}

** Correlation is significant at the 0.01 level (2-tailed)

* Correlation is significant at the 0.05 level (2-tailed). 


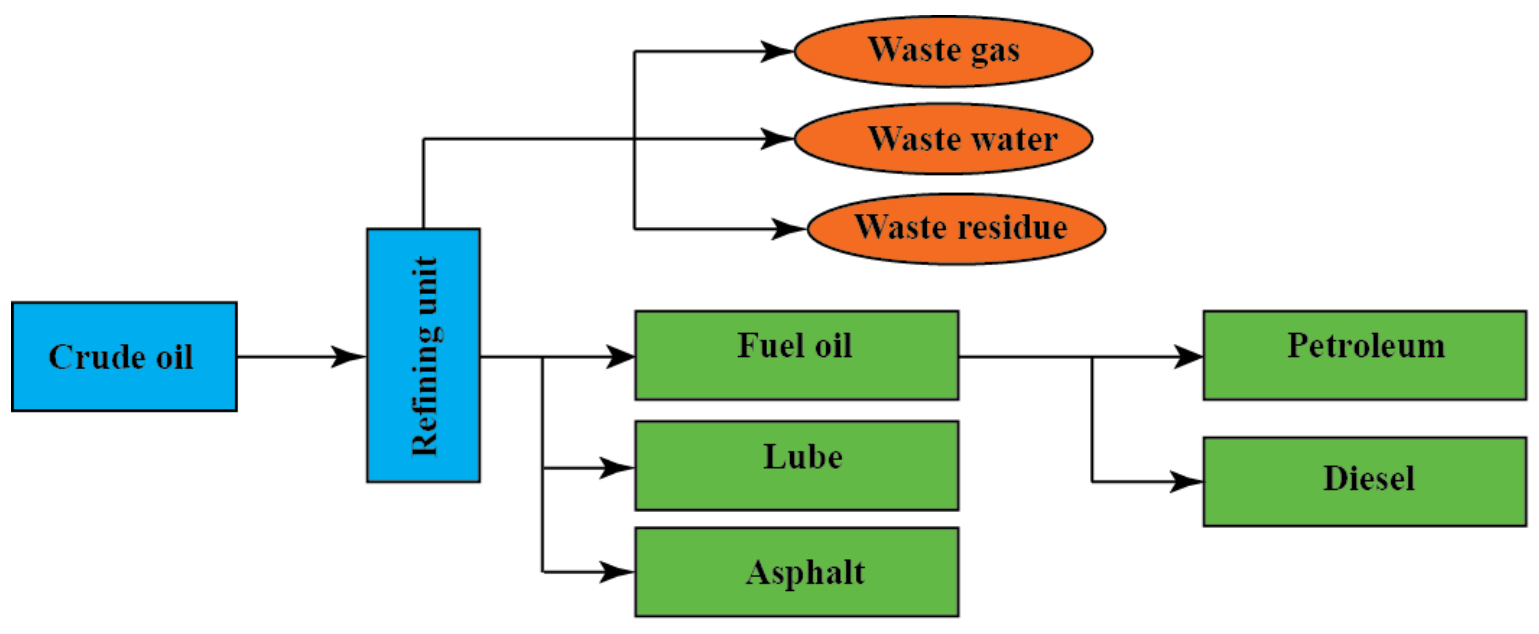

Oil refinery

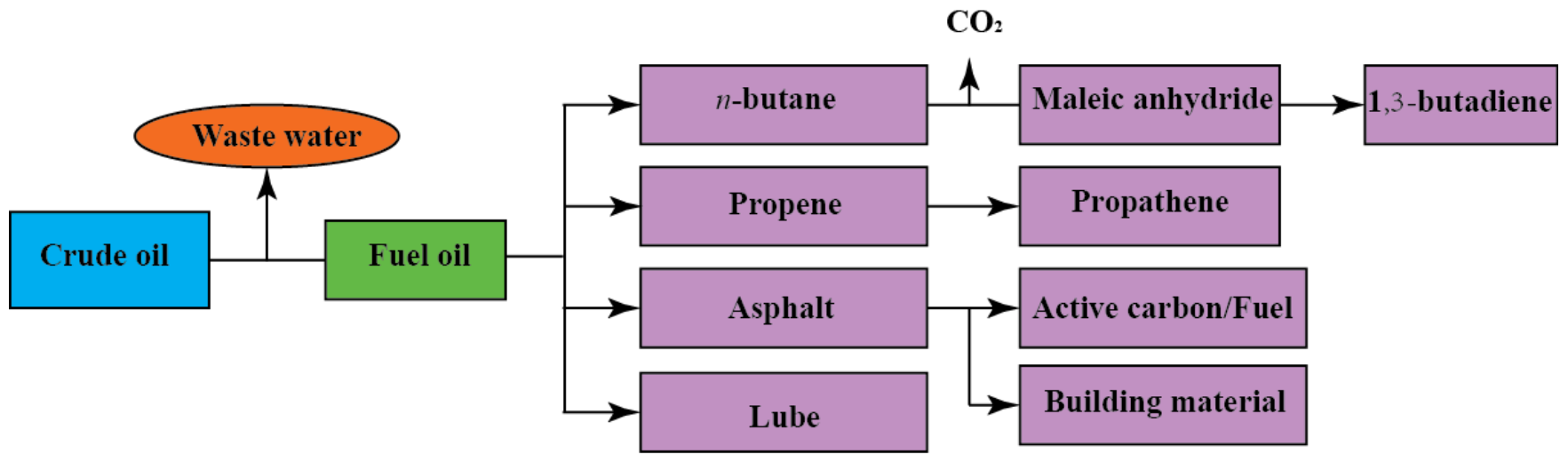

Petrochemical industry

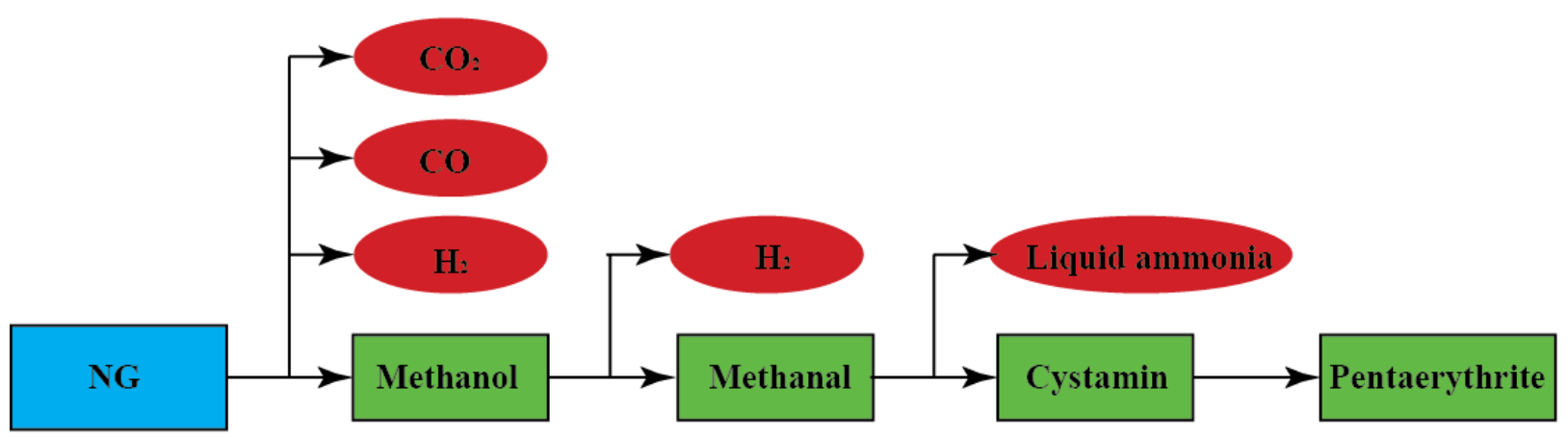

NG chemical industry

Figure S1. Flow charts of the main petrochemical industrial processes in study area. 


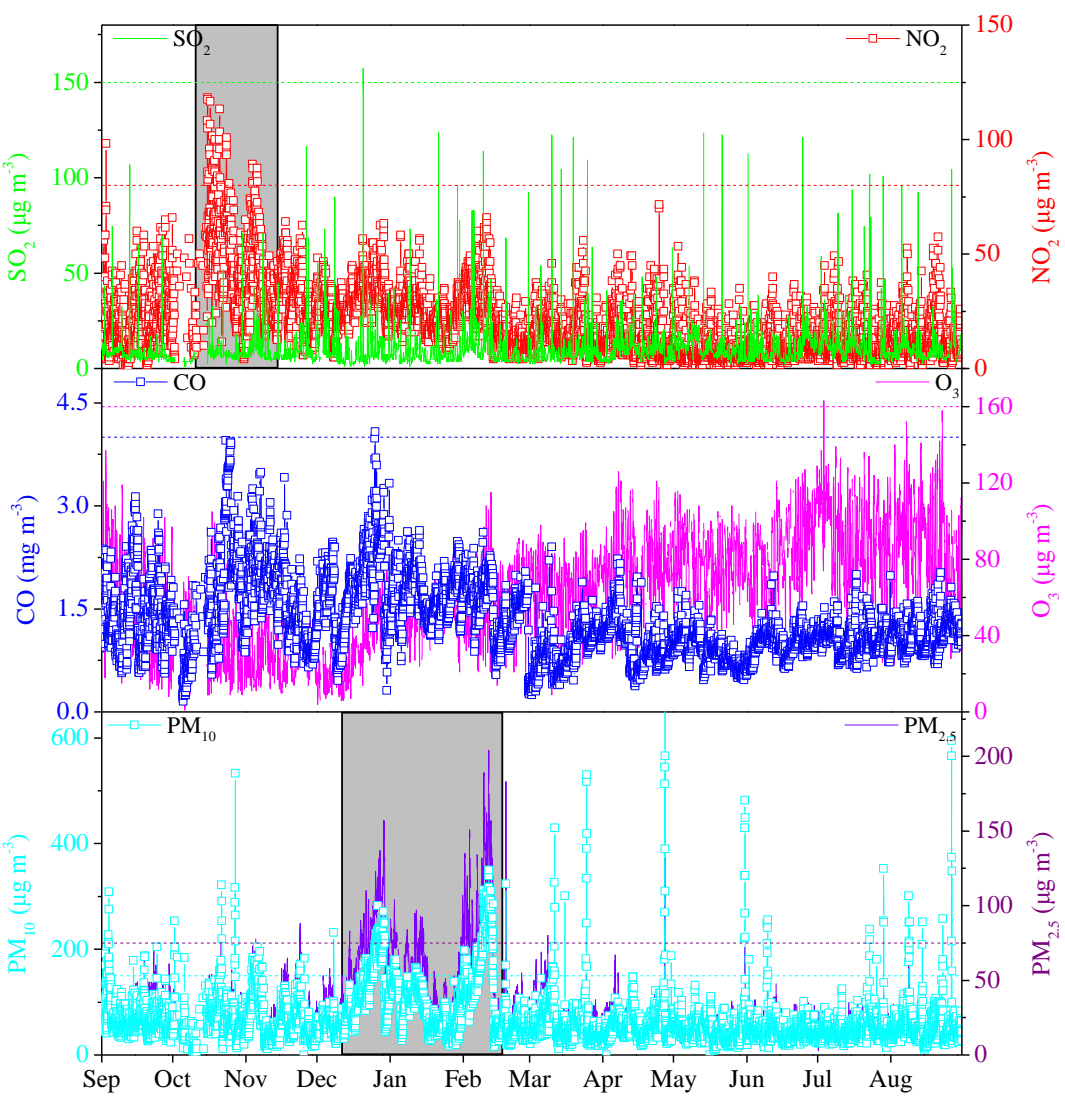

Figure S2. The hourly air pollutants concentrations during the whole sampling period from September 2014 to August 2015. The horizon dash lines represent the Ambient Air Quality Standard II (GB/3095-2012). 


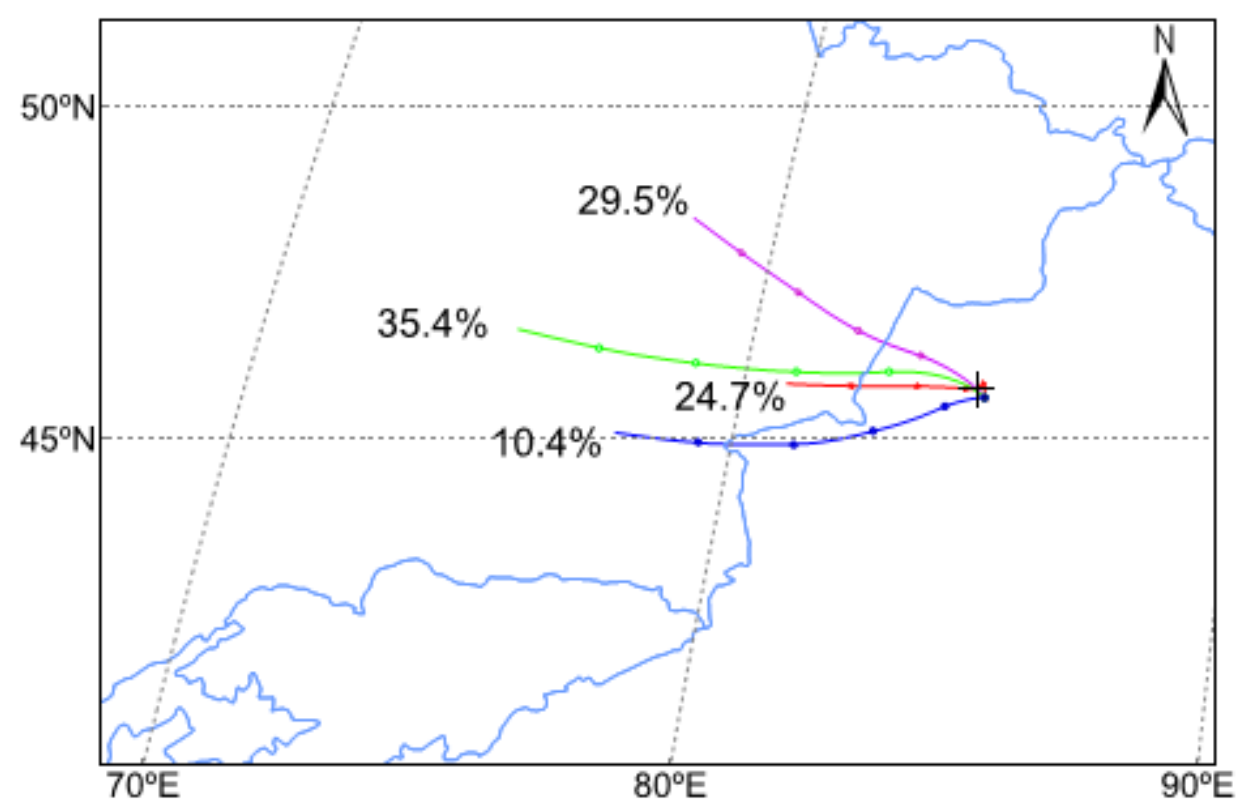

Figure S3. Average trajectories obtained after clustering analysis and the percentage of clusters (\%) from different directions during the sampling period from September 2014 to August 2015. 

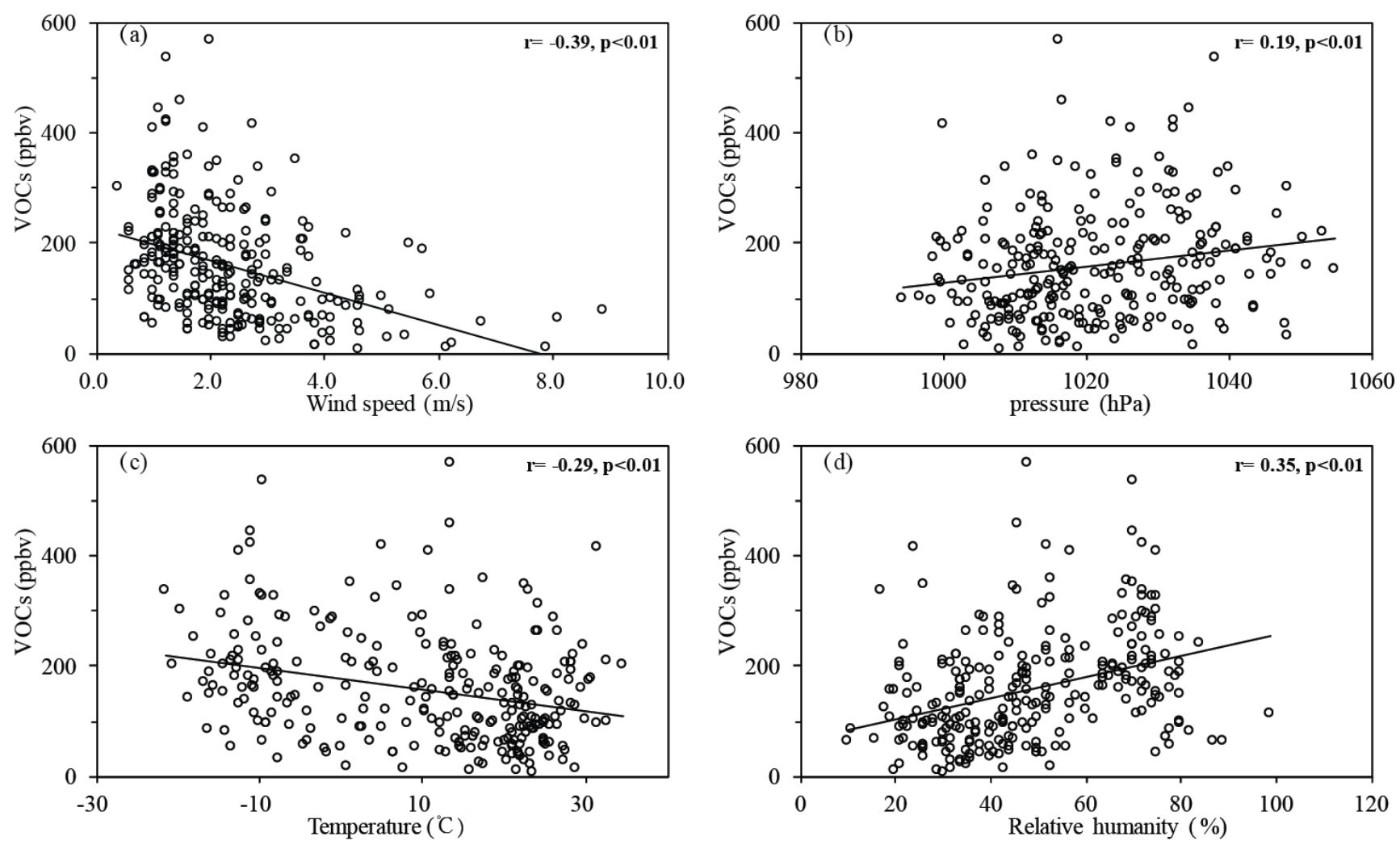

Figure S4. Scatter plots between daily VOC concentrations and metrological parameters including wind speed (a), pressure (b), temperature (c), and relative humidity (d) 

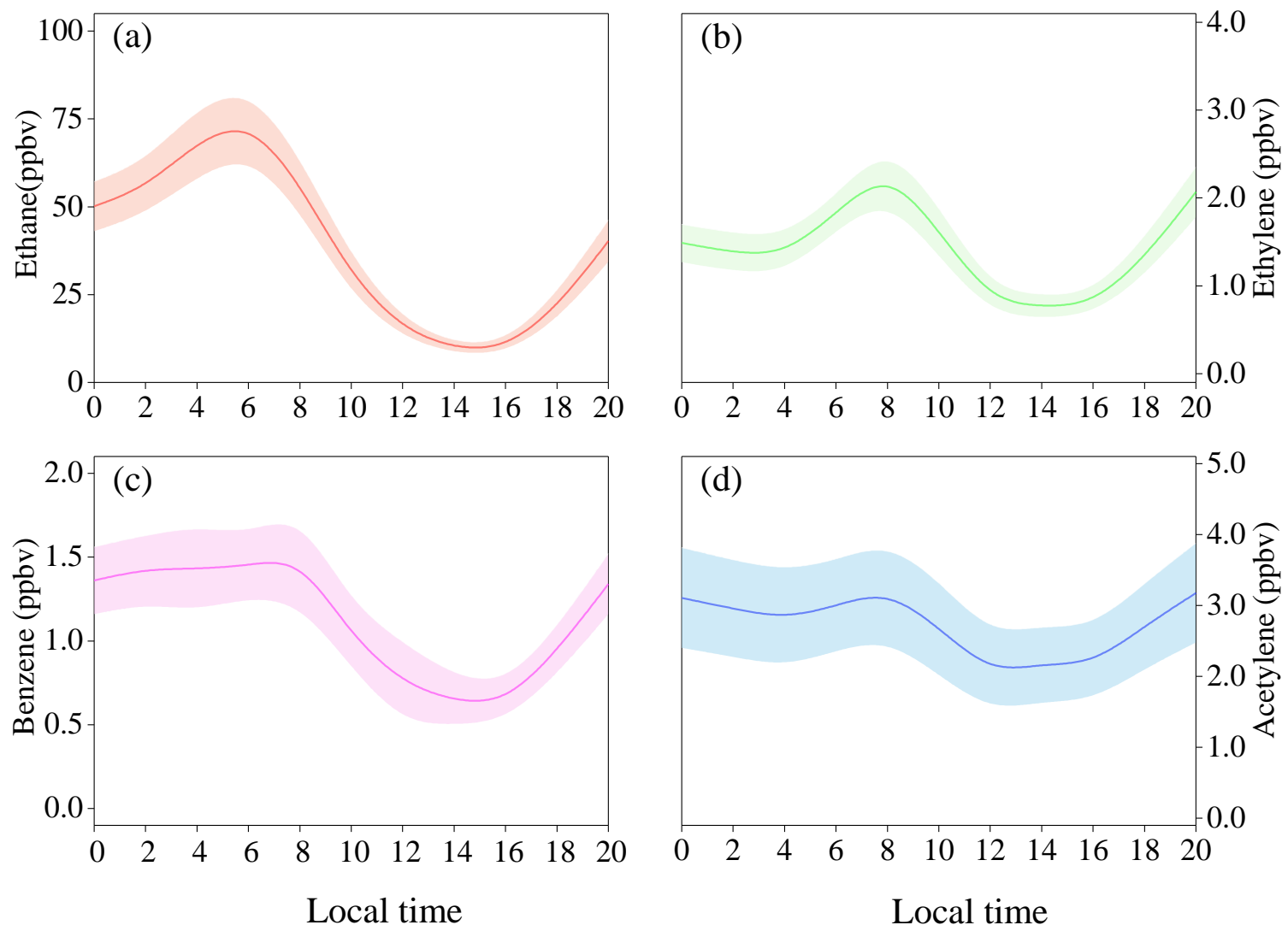

Figure S5. Diurnal variations of ethane (a), ethylene (b), benzene (c), and acetylene (d). Solid line represents the average value and filled area indicates the 95 th confidence intervals of the mean. 

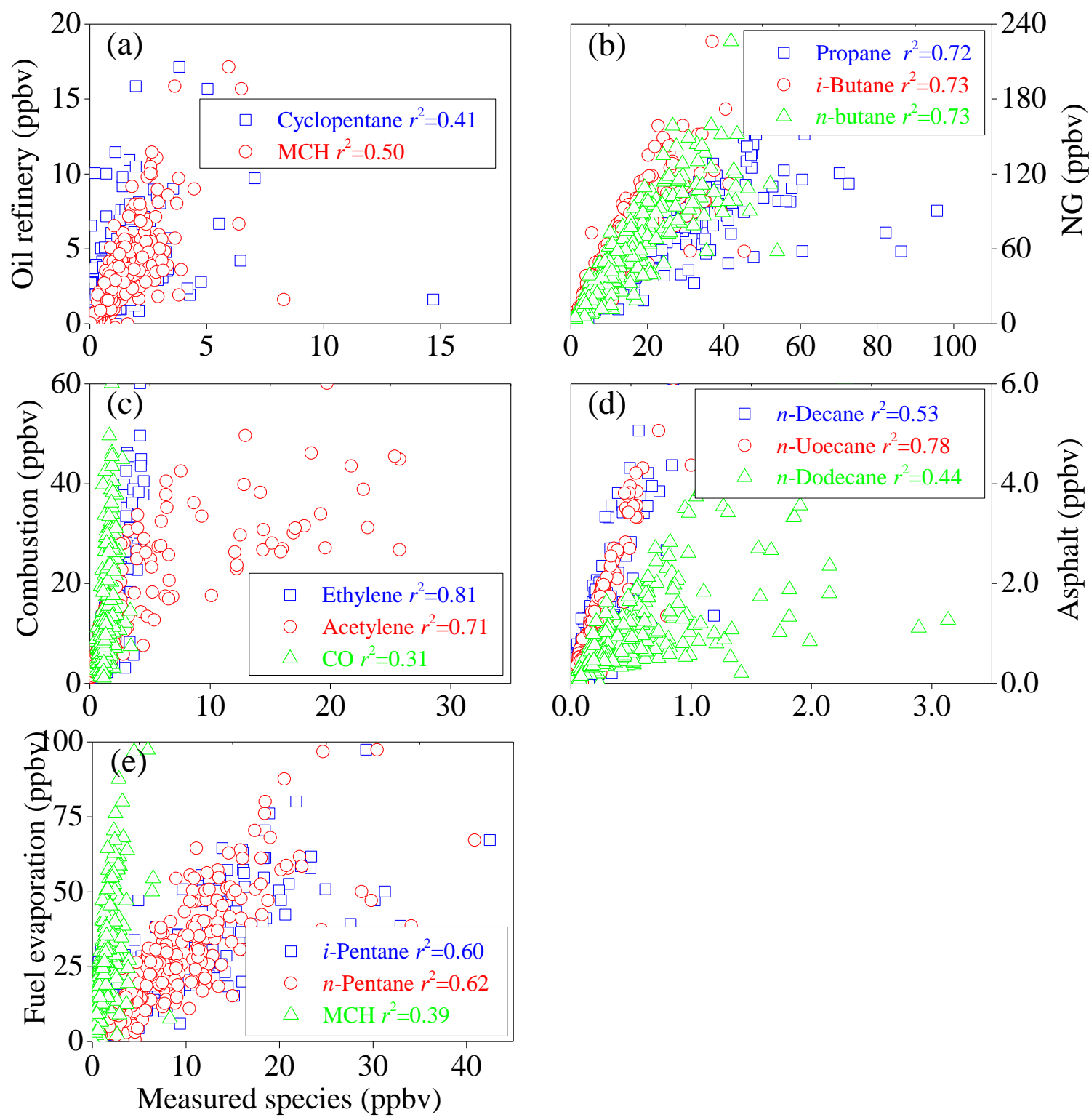

Figure S6. Scatter plots between five identified VOC source contributions and and their high loading species in their corresponding source profiles. Oil refinery (a), NG (b), combustion (c), asphalt (d), and fuel evaporation (e). 

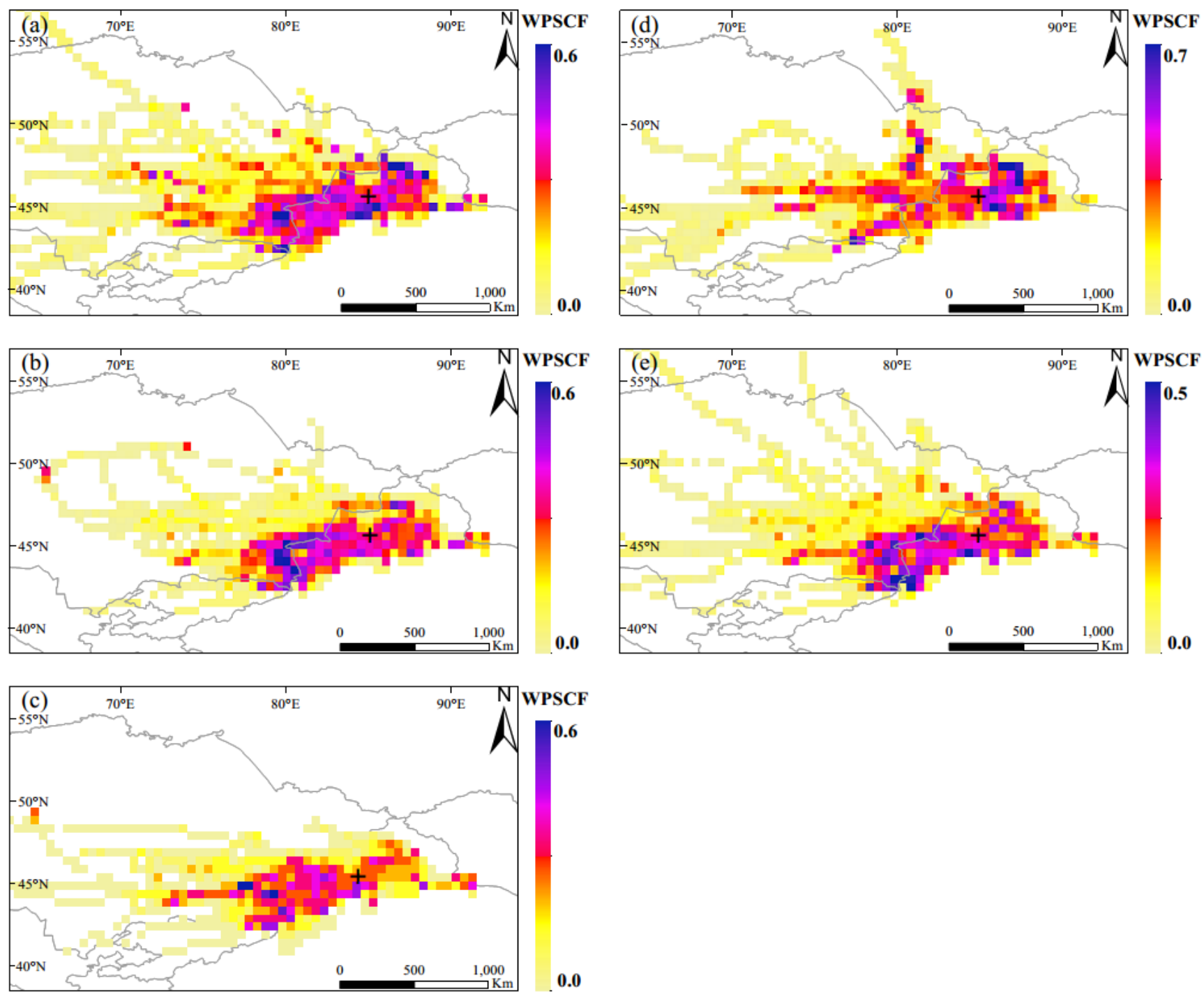

Figure S7. The WPSCF maps for five identified sources derived from PMF analysis: oil refinery (a), NG (b), combustion source (c), asphalt (d), and fuel evaporation (e) in autumn. The black cross represents the sampling site. 

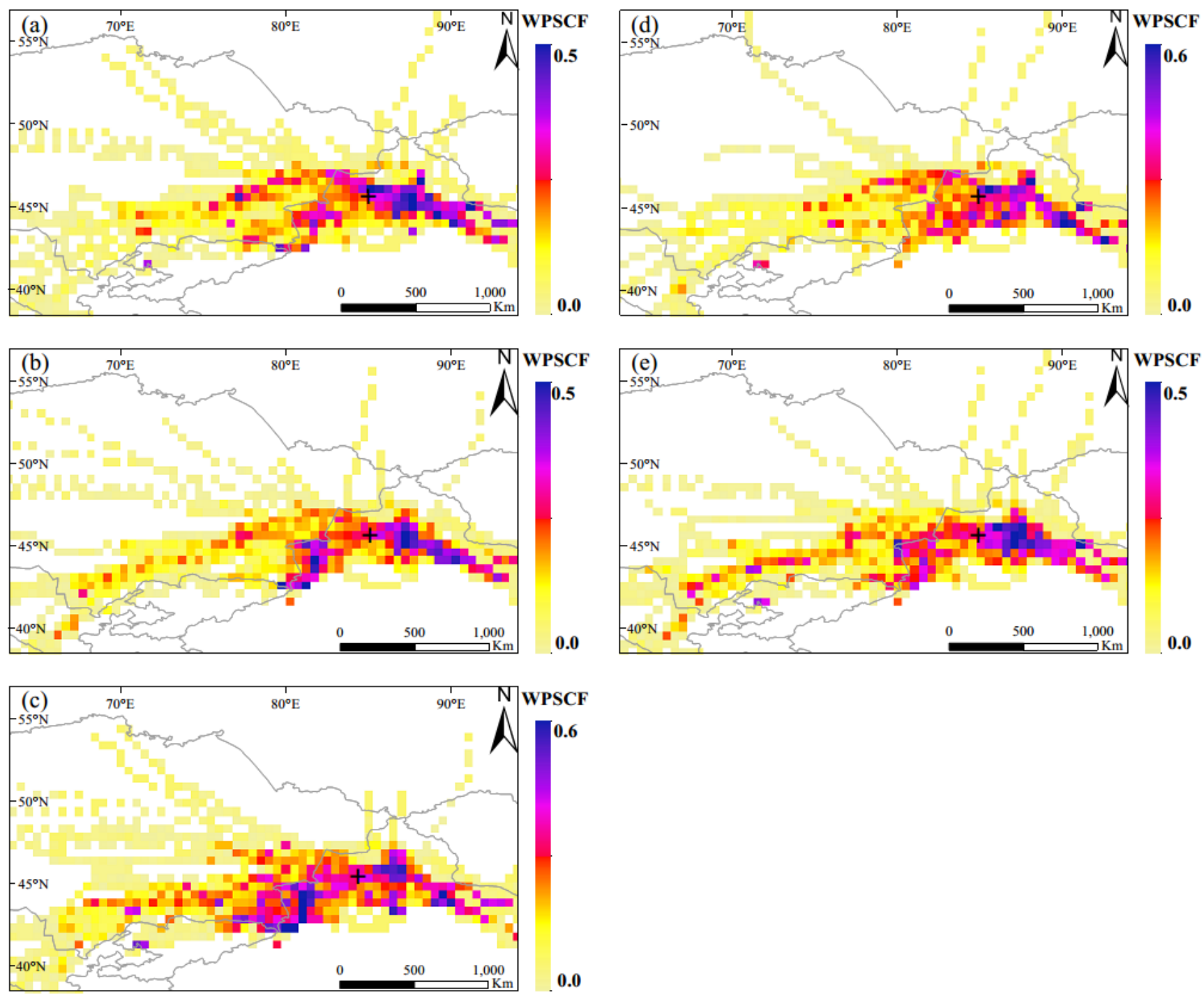

Figure S8. The WPSCF maps for five identified sources derived from PMF analysis: oil refinery (a), NG (b), combustion source (c), asphalt (d), and fuel evaporation (e) in winter. The black cross represents the sampling site. 

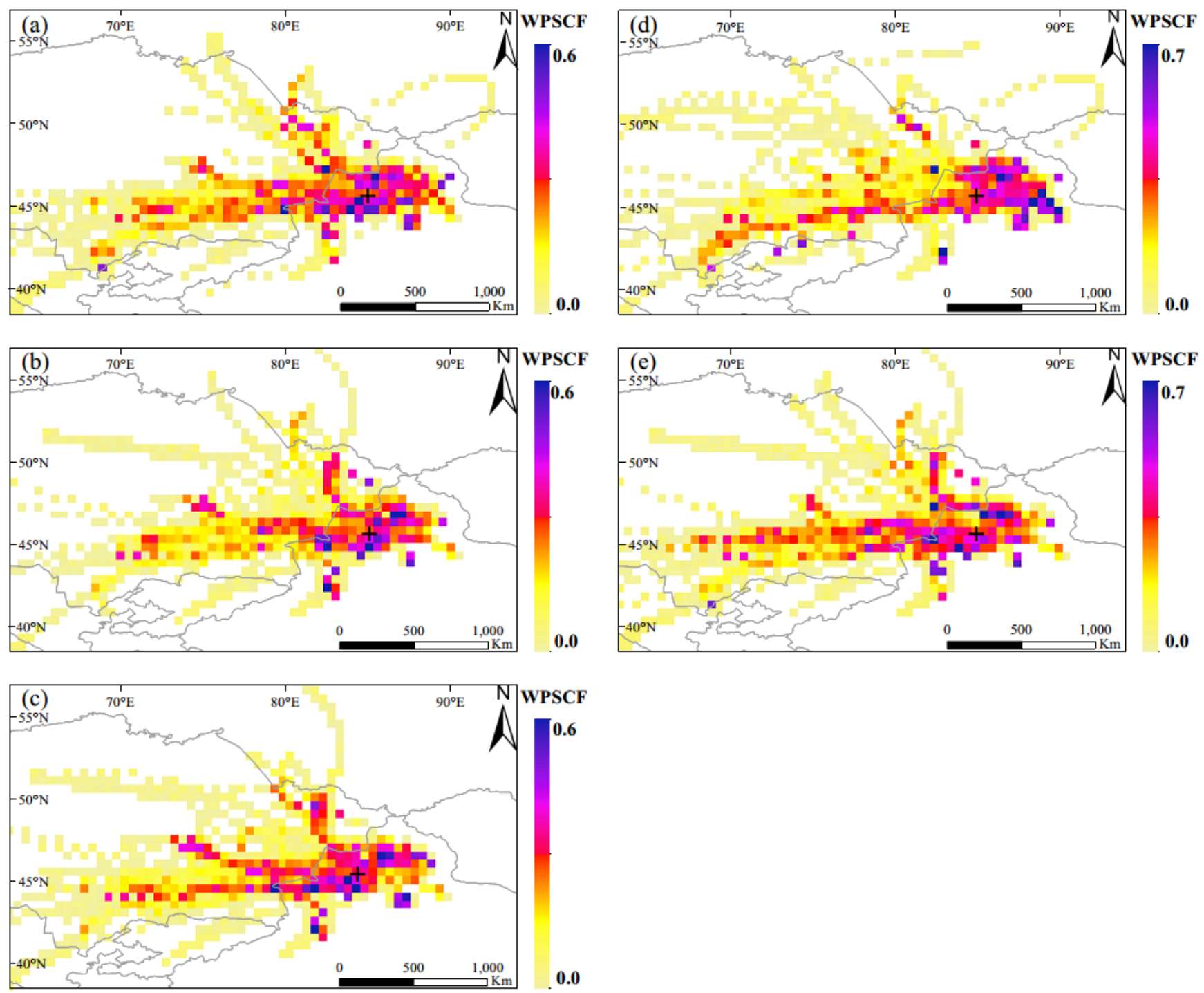

Figure S9. The WPSCF maps for five identified sources derived from PMF analysis: oil refinery (a), NG (b), combustion source (c), asphalt (d), and fuel evaporation (e) in spring. The black cross represents the sampling site. 

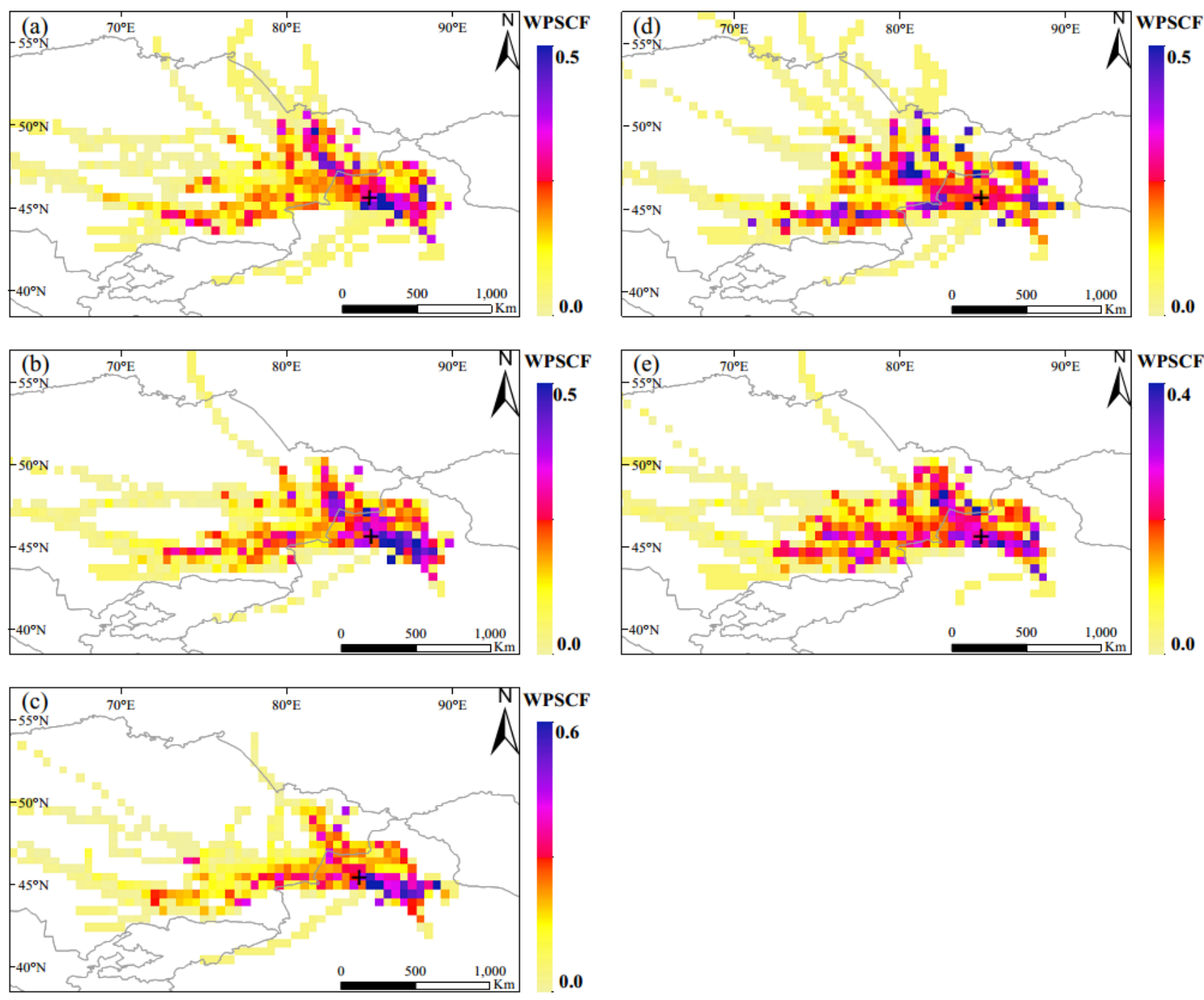

Figure S10. The WPSCF maps for five identified sources derived from PMF analysis: oil refinery (a), NG (b), combustion source (c), asphalt (d), and fuel evaporation (e) in summer. The black cross represents the sampling site. 

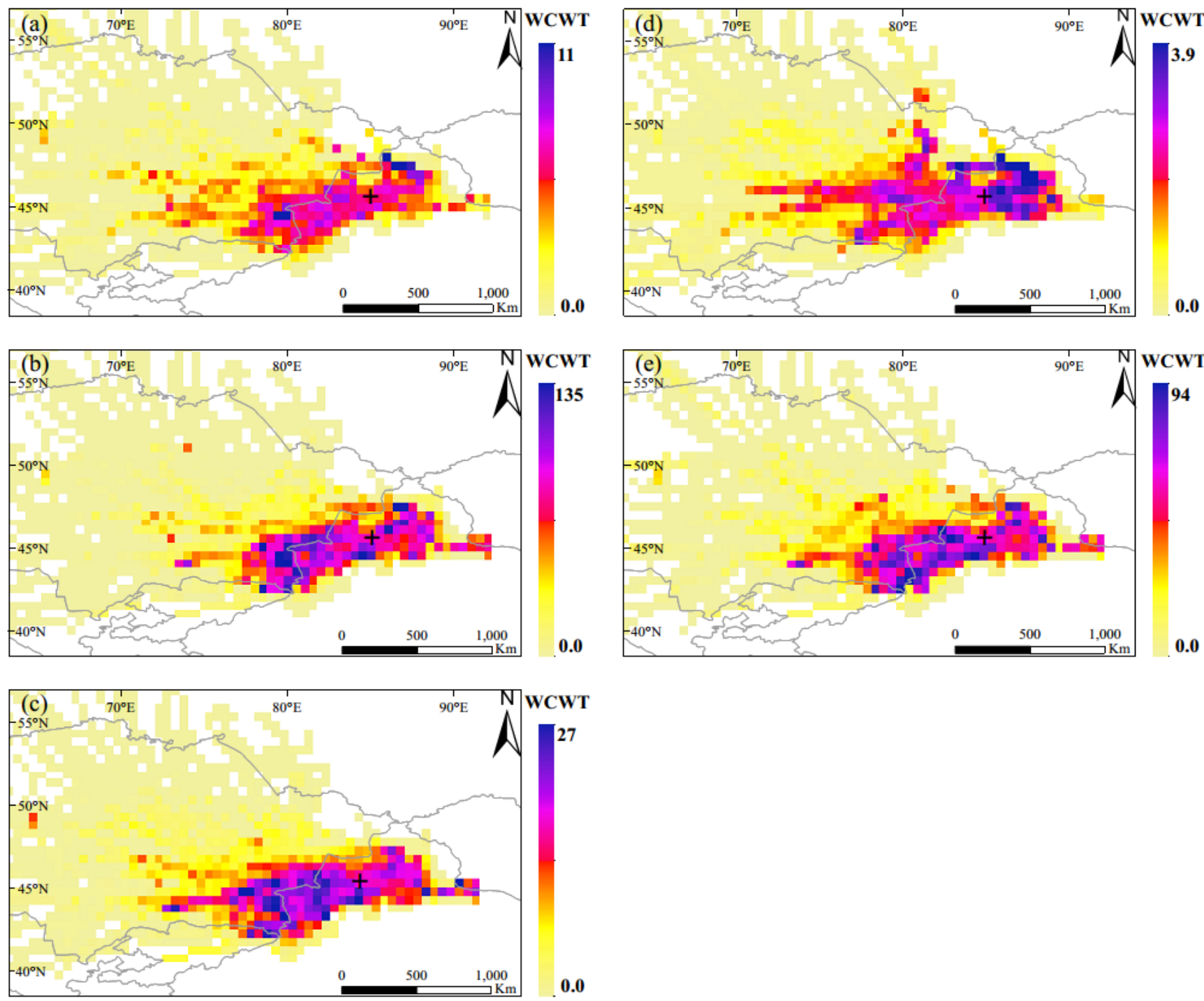

Figure S11. The WCWT maps for five identified sources derived from PMF analysis: oil refinery (a), NG (b), combustion source (c), asphalt (d), and fuel evaporation (e) in autumn. The black cross represents the sampling site. 

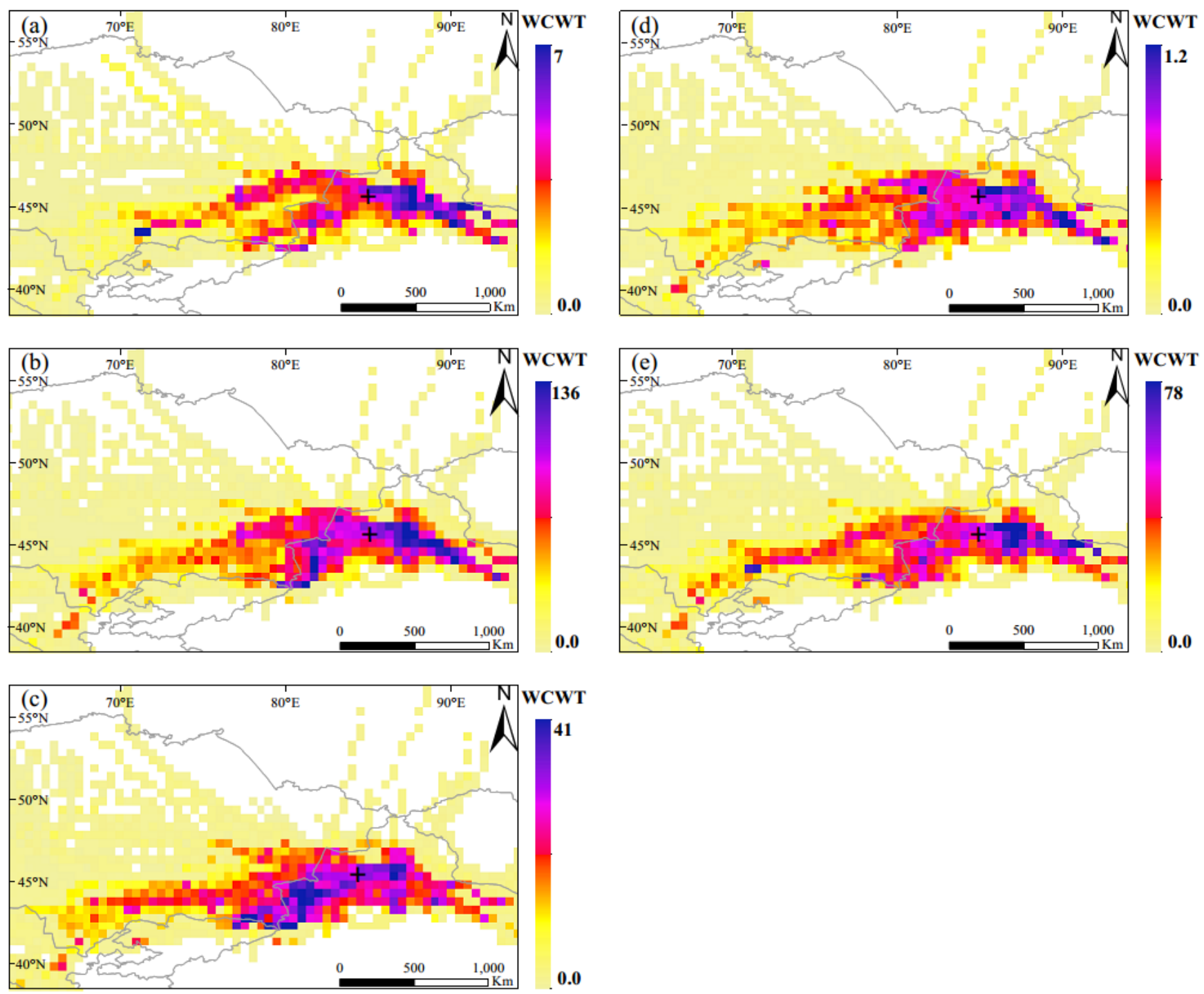

Figure S12. The WCWT maps for five identified source derived from PMF analysis: oil refinery (a), NG (b), combustion source (c), asphalt (d), and fuel evaporation (e) in winter. The black cross represents the sampling site. 

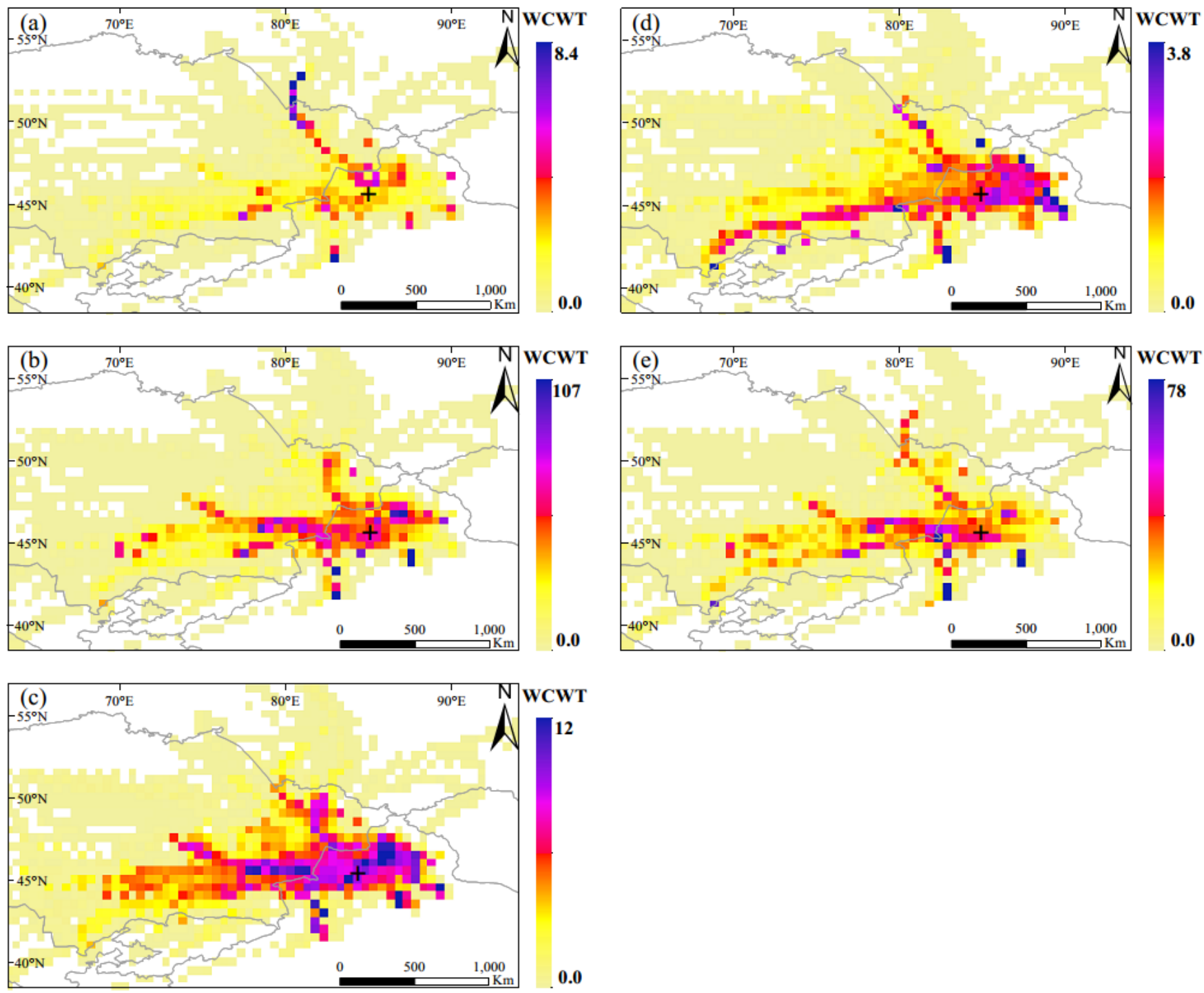

Figure S13. The WCWT maps for five identified source derived from PMF analysis: oil refinery (a), NG (b), combustion source (c), asphalt (d), and fuel evaporation (e) in spring. The black cross represents the sampling site. 

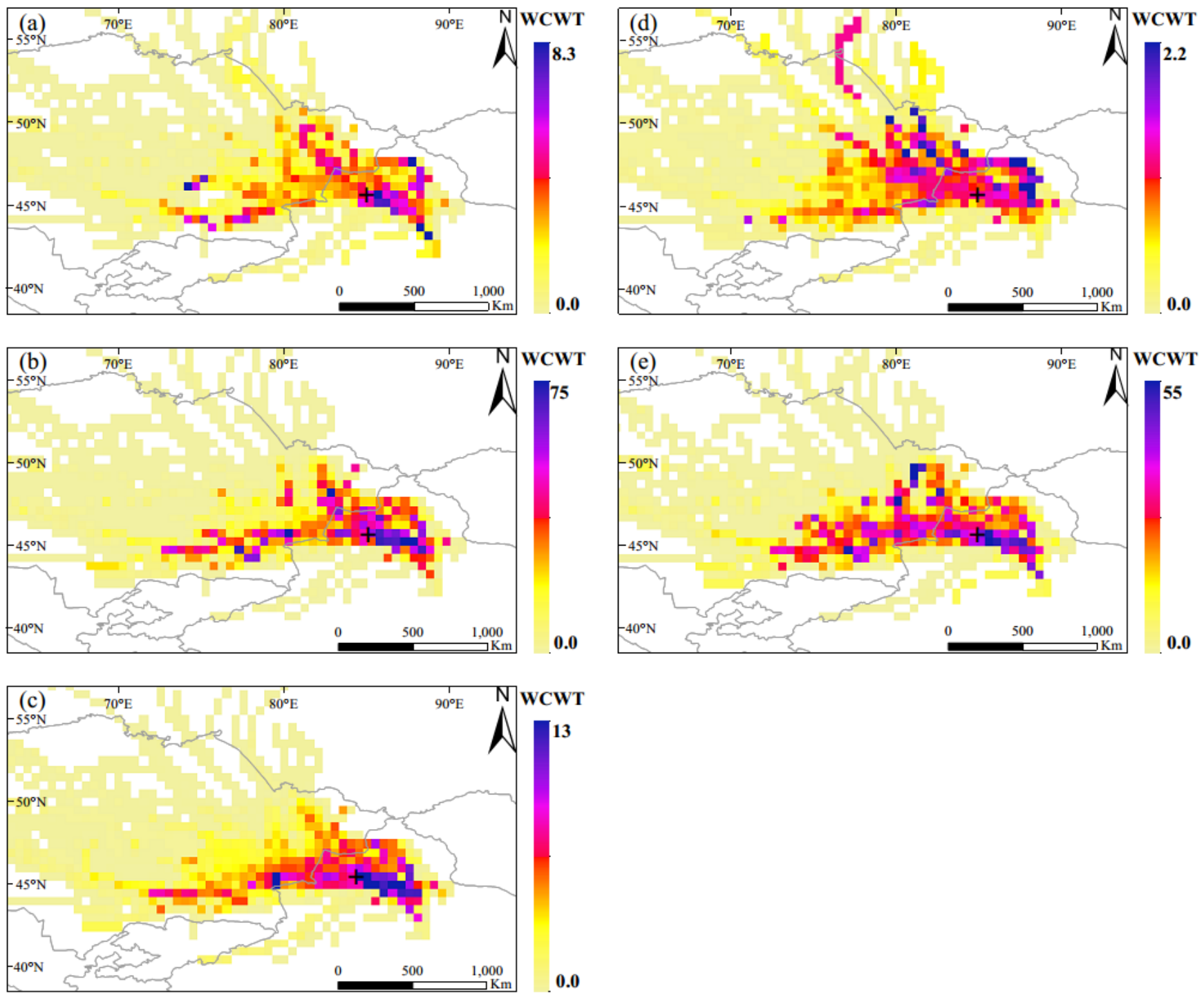

Figure S14. The WCWT maps for five identified sources derived from PMF analysis: oil refinery (a), NG (b), combustion source (c), asphalt (d), and fuel evaporation (e) in summer. The black cross represents the sampling site. 